\title{
Developing cross-cultural communicative competence via computer-assisted language learning: the case of pre-service ESL/EFL teachers
}

\author{
Abdelilah Salim Sehlaoui \\ Deportment of Foreign Languages, Emporia State University \\ email: sehlaoua@emporia.edu
}

\begin{abstract}
Based on a qualitative research project, this article presents a view on the use of computer technology to develop a critical cross-cultural communicative competence in English as a Second Language (ESL) / English as a Foreign Language (EFL) for preservice teachers. The article includes a brief critical theoretical framework, some classroom pedagogical implications, and a data-based discussion of pre-service teachers' vicws. These views included: (1) critical views and an awareness of cultural power relations in computer-assisted language learning (CALL), (2) uncritical views and a lack of awareness of cultural power relations in $C A L L$, and (3) uses of metaphors in $C A L L$. The powerful contribution of CALL can be found in its potential for providing ways to connect people and build communities, for offering opportunities for crosscultural communicative competence to be developed and used, and for improving processes of democratization via computer-mediated communication. However, a sociocultural criticism revealed that this powerful tool, like any other media, is non-neutral because it can serve to reinforce further the hegemonic aspects of education, that is, the dominant culture will be strengthened and protected via computer technology. Computerbased technologies and software are increasingly incorporated into the curricula of ESL/EFL teacher education programmes. However, this integration is often done in ways that seem to leave unquestioned the potential cultural and hegemonic ramifications of such technology. Hence there is a need for a more critical technological competence.
\end{abstract}

\section{Introduction}

A review of the relevant literature strongly suggests that many, if not most, English as a Second or Foreign Language (ESL/EFL) teacher education programmes typically utilize 
concepts of culture and strategies for teaching and learning that are open to some cogent, but constructive, critiques from the perspective of critical educational theory. In addition, according to Wise (1995), throughout the last ten years the National Council for Accreditation of Teacher Education has required that colleges of teacher education must integrate technology into their curricula. In fact, ESL/EFL teacher education programmes are increasingly incorporating computer-based technologies and software into their curricula. However, this integration is often done in ways that seem to leave unquestioned the potential cultural and hegemonic ramifications of such technology (see, for example, Bowers, 1988; Jones, 1995; Morton, 1996; Murray, 1997; Sehlaoui, 1999).

The purpose of this article is to argue for the need for a critical computer literacy in the process of developing cross-cultural communicative competence in English as a Second/ Foreign Language (ESL/EFL) pre-service teachers. To achieve this purpose, this article presents a brief theoretical framework, a data-based discussion of ESL/EFL pre-service teachers' views and some classroom pedagogical implications.

\section{Background information}

The argument developed here is supported by the findings of a dissertation research project. The primary purpose of this research project was to describe and analyse current practices in an MA TESOL (Teachers of English to Speakers of Other Languages) programme in terms of the programme's efforts to develop cross-cultural communicative competence in students enrolled in the programme. The term cross-cultural communicative competence will be referred to in this article as CCCC. The way in which CCCC is defined and developed within the programme was thus an important, but broad domain of enquiry. Within this overarching domain, the purpose of the research focused on the conceptualizations of culture utilized within the programme, the professional and cultural identity formation processes that appear to be occurring, the characterization of students' analyses of power relations and their own position within these relations, and the ways in which computer-based technologies are being increasingly incorporated as a part of these processes (Sehlaoui, 1999). This article focuses on the last component of this research project, the role critical computer literacy plays in the process of developing CCCC in ESL/EFL pre-service teachers. Based on students' perspectives, beliefs and attitudes - as described in Sehlaoui (1999) - data-based pedagogical suggestions will be made.

\section{Methodology}

A qualitative research framework was chosen for this study. In order to examine how the development of CCCC was being approached in the MA TESOL programme at a state university in the USA, data were obtained by: (1) classroom observations in the three core courses for which the instructor's and students' permission had been obtained, (2) questionnaires given to graduate students who chose to participate in the study, (3) analysis of programme documents and materials such as syllabuses, software programmes used, etc., and (4) semi-structured interviews with MA TESOL students who gave their consent. A domain/thematic analysis, based on the initial research questions, was performed by generating categories and then themes from the answers given by the responders, the classroom observations field notes data, and by examination of the written documents (Ely, Anzul, Friedman, Gamer and Steinmetz, 1991; Miles and Huberman, 1994). 


\section{Participants}

The total number of participants in this study was twenty-seven: nine males and eighteen females. Their age range was between twenty-three and forty-five. The participants were from ten different countries: China, Taiwan, USA, Belize, Japan, Korea, Argentina, Thailand, Saudi Arabia and Jordan. The majority of participants (twenty-three) in this study came from a middle and upper-middle social class and only two from a low and lower-middle social class.

\section{Setting}

The natural context in which the present research project was carried out is the English Department at a state university in the USA. The target programme was the MA TESOL programme, which focused on ESL/EFL pre-service teachers and ESL/EFL teacher educators' classroom learning/teaching practice.

\section{A critical theoretical framework}

The theoretical framework which guided the analyses and interpretations of data is grounded in critical educational theories that have emerged from the field of multicultural education and have often provided a basis for change in teaching and learning strategies relating to cultural dynamics (Aronowitz and Giroux, 1993; Foley, 1990; Giroux, 1981; Sleeter and Grant, 1999; Shannon, 1992; and Tidwell, 1993). In many ways, the proposed research was an attempt to draw together elements from the areas of multicultural education and TESOL with an eye toward benefiting both of these fields of scholarship and practice. The special focus of this study on computer technology in the curriculum and its implications for socio-cultural dynamics is a recognition of technology's increasing, and often unquestioned, role in socio-cultural processes.

Until quite recently, computer-assisted language learning (CALL) was a topic of relevance mostly to those with a highly specialized interest in that area. Recently, though, computers have become so widespread in schools and homes of middle- and upper-class families (Lockard, Abrams and Many, 1997; Poole, 1997) and their uses have expanded so dramatically that the majority of language teachers must now begin to think about the implications of computers for language learning and teaching (Warschauer, 1996). From a critical perspective, it is important to recognize that computer use is non-neutral, in the most basic sense, because not all students in a society have equal access to computers (Lockard et al., 1997). This will inevitably create a new category of 'haves' and 'have nots', usually along pre-existing lines of inequalities. According to McGrath, Thurston, McLellan, Stone and Tischhauser (1992: 468), inequities in computer access have two implications: 'First, the students affected will be educationally handicapped by the lack of powerful learning tools ... Second, these students may find themselves at a disadvantage in their preparation for their future academic careers or jobs'.

In a more globally cultural sense, computer programs, according to Bowers (1988), carry with them the inherent mechanical mode of thinking that underlies the western approach to science and technology. While western languages, especially English, have developed in a complex historical relationship to a positivist world-view, the form and structure (and philosophical ethos) of many languages exist at odds with, or at least in a different relationship with, more mechanistic structures and forms. 
Pennington (1996) points out that while computer use in language learning can promote positive learning experiences, it can also encourage a form of anti-social behaviour. Like Bowers and Pennington, Jones (1995) discusses the kind of culture that is being developed in what he calls 'cybersociety'. In other words, we need to be aware of the type of reality and world-view that computer-mediated communication (CMC) can bring with it. These authors point out that we must be aware that instead of developing students' CCCC via email and Internet, this computer use may be developing a new elite culture and fostering students' stereotypes and biases, especially when the focus is on cultural products rather than process. Computer technology can hinder cross-cultural communication by exposing students and teachers to cultural material that can develop or strengthen stereotypes and prejudices rather than reduce or eliminate them.

Educators' unawareness of these forms of non-neutrality can serve to reinforce further the hegemonic aspects of education, that is to say, the dominant culture will be strengthened and protected via computer technology, since it is the dominant social classes and their cultural forms that will both shape and benefit most from this technology. In other words, structural inequalities will be perpetuated through both of these aspects. However, in spite of this sociocultural criticism, computer technology has offered the field of education a powerful tool for learning and teaching, and does hold some potential for the furtherance of processes of democratization.

The powerful contribution of CALL can be found in its potential for providing ways to connect people and build communities, in offering opportunities for CCCC to be developed and used, and for improving processes of democratization via $\mathrm{CMC}$. However, a sociocultural criticism revealed that this powerful tool, like any other media, is nonneutral. The following section presents a data-based sociocultural analysis as it emerged from the research project by Sehlaoui (1999).

\section{A data-based sociocultural analysis: computer technology, culture and power}

Computer technology, culture and power emerged as a separate category in the research project. This category addressed the following research question: how is computer technology discussed and conceptualized among students as part of their socialization process in the programme? How is this technology integrated in the TESOL programme?

The data collected by means of observation and document analysis did not contain any reference to CALL. This means that during all observation sessions of three core courses in the TESOL programme, CALL was not among the topics discussed or studied (apart from a few instances when one of the instructors mentioned to the students that he had sent an email message with some instructions and class announcements). Furthermore, the textbooks used in all three courses did not integrate CALL into their content (see, for example, Celce-Maurcia, 1991; Gebhard, 1996; Ramirez, 1995; Samovar and Porter, 1994; Ur, 1996). These observations about CALL in this particular programme are so significant because they corroborate the findings in the other two resources, namely, the interview and questionnaire data.

Three main themes emerged under this category in interview and questionnaire data: (1) critical views and an awareness of cultural power relations in CALL, (2) uncritical views and a lack of awareness of cultural power relations in CALL, and (3) uses of metaphors in 
CALL. These themes emerged in the data collected during the interviews with the participants, as well as their responses to the questionnaire.

\section{Critical views and awareness of cultural power relations in CALL}

The following statement, by a student from Thailand, illustrates the critical views held by some informants:

Now most of Internet is used by rich people. People in schools and even now some colleges do not have Internet. Internet can change a lot. It's creating the change. It's influencing our culture. You know when I was in my country I didn't know about it, but I know that it has good and bad sides. I mean good in transferring knowledge and bad because it encourages nudism in my country.

This echoes the attribute of 'double-edged sword' used by some participants in the study to describe the cultural changes in the world (see Sehlaoui, 1999). The same informant added: 'OK, technology is one of the causes of this change. As a means of communication it helps a lot in those changes.' Relating this to the hegemony of the English language and culture, another informant raised the question of whether all the people using Internet should know English. He explained:

The idea would be that they try to do this so that everything on the Internet should be in English so that all the people should know English or should learn English. I would say that the point of arabizing or electronic arabizing is difficult because it is not desirable for the dominant culture . . . Electronic arabizing would be $\mathrm{OK}$ and accurate. It's necessary to know the English language; therefore, the effort of arabizing is not encouraged because they want people to learn the American culture. If there is no translation, people will need to learn the English language and if they learn the language they must learn the culture too.

This is another form of hegemony that supports the dominant culture, which has been described as linguistic imperialism (Phillipson, 1992). Such cultural criticism as it relates to computer technology should become part of the TESOL curriculum. In another country, the use of the Internet was explained by a participant who said that:

the system, as far as I know, is not working yet on a wide range. It's something closed for university staff or something like that. The public cannot have access for using the Internet and if they can use it, it's expensive for them (people who cannot afford it). And as far as I know there are regulations for displaying material there. The information will be filtered. It will be censored. Things like pornography. I think it's hard to control political information, though. It's not something like sex. The system itself will be programmed not to allow something like this to get through.

From the USA a student said that:

the dominant culture has more access to it. Like I said the middle-upper income class. Those lower-income/poverty class don't have access and I have seen that with my own eyes ... yeah. This closes the door to them, they can't improve socially and economically. I see that in the future, this is gonna be more and more important in our life, but the gap is gonna get larger and larger, especially when they don't teach technology and don't make it available. 
This supports the implications made by McGrath et al. (1992) about inequities in computer access.

Two different students (who apparently belong to two different socio-economic classes) explained their experiences with computer technology as follows. One Saudi student said:

For example, I was browsing the Internet last night looking for some software for qualitative research and $I$ found some of them that can code video-taped material and everything. I think this kind of software helps the researcher in doing all his/her research, for example, in months or weeks, you can do that in $90 \%$ less time which is good.

In contrast, a US student explained that

when the university is closed down that has been a problem for me because I don't have access to it at home. It's very frustrating. That was the one thing I was concerned about. I was still looking for a job and I was getting nearer and nearer to the end of the semester and I was communicating with a lot of people through email and I was ' $\mathrm{Oh}$ my Gosh! What am I gonna do?' And a friend offered that I could use her email but I have to drive twenty miles to get to her house.

2. Uncritical views and a lack of awareness of cultural power relations in CALL Although the above participant showed an awareness of the issue of equity and accessibility of computers, she was not that critical about computer use in the classroom and in relation to CCCC and its cultural dynamics. The following statement illustrates this uncritical view:

The students can use it to learn all about other cultures on the Internet, type the name of the country and ... I have not thought a lot about that. I would teach culture through Internet like if that was a course based on culture or maybe if I give an assignment on culture I would recommend the use of Internet maybe there might be a specific site where they can explore other cultures. I'm not really sure how I would use it.

This statement also shows a lack of confidence in how to use computers in developing CCCC in EFL/ESL contexts. This can be ascribed, partially, to the lack of training that ESL/EFL teachers have in this area (see, for example, Morton, 1996; Warschauer, 1996). The following statement illustrates this further, when the informants were asked to describe their experiences with CALL:

Not much. I have very little experience with computer technology. My abilities, that I developed on my own, include word-processing, some understanding of email and Internet usage. My knowledge is very basic, though I would like to know more.

Another informant explained '[he is] learning a lot from computer technology on [his] own'. This informant's statement also shows that educational technology is still a weak component for most ESL/EFL educators, since most students said they were learning how to use computers on their own. This fact was confirmed by field note data and document analysis data as mentioned before. This triangulation of data analysis also helped in tracing the conceptualizations of culture used in the participants' responses to the use of CALL in developing CCCC. 
Statements about computer use in relation to cultural learning and teaching were also based on the conceptualization of culture as country, too. Within this category the themes of computer neutrality and culture as country or artefact occurred. Culture is equated to country as is shown in the following statements about CALL. One participant stated: 'it's wonderful you can communicate across the boundaryless world, not knowing or caring if the person is racially, ethnically, culturally the same or different from you. It gives students a lot of practice in writing and understanding.' To illustrate this general perception of the 'culture as country' and 'the neutrality of computers', one of the participants stated:

Well, for me, it provides people with a way to communicate with people in other countries or other cultures. Beyond that, I am not really sure. I do think that it's easier and more comfortable talking/communicating with people who are different on the computer because you're not facing them, the differences can be ignored.

This is what Jones (1995) and Bowers (1988) addressed in their cultural criticism of educational computing. The same uncritical views and perceptions were evidenced by the data collected during a pilot study that anticipated this dissertation research project. In their responses to the following statement, 'Computer technology can be used to develop CCCC because it is neutral', almost all participants ( 80 per cent) agreed that computer technology is neutral in the sense that has been discussed before in this article. Only 5 per cent disagreed with the statement above, whereas 15 per cent had no opinion.

\section{Uses of metaphor in CALL}

Another recurring theme in this study was that of metaphors used by participants to describe the role of computer technology in developing CCCC. These metaphors included: 'the computer's ability to break down cultural walls', 'it [the computer] brings the world into a small global village', 'it [the computer] brings your culture to the tips of your fingers', 'the Internet acts as a window to information about the cultures of the languages studied'. The metaphors that were used or adopted by some informants while talking about technology, during interviews, included: 'the world becoming a small village', 'I think technology makes the world smaller as they call it "a global village"', "computer and language are tools'. In support of Murray's (1997) cultural criticism of the uncritical use of metaphor in CALL, one of the participants said:

$I$ believe that computers and the Internet are changing our world and people from all around the global village are becoming closer. So intercultural communication is the field of the future.

This statement is an example of the uncritical acceptance of 'the village' metaphor, that is, a village comprised only of those who have access to computers (Murray, 1997).

According to Murray (1997), as language educators, we need to unravel the metaphors used to talk about computer technology because the metaphors used constantly in our everyday language shape our understanding and view of the world. She points out that many of the terms and metaphors used to describe the new technology, such as the ones used by the participants in the study reported in this article, lead us to ignore the social context in which the technology is introduced. Murray states that "what these metaphors hide is the historical fact that the introduction of all new technologies is not socially or morally neutral. It takes place in a social and cultural context that helps determine how it 
will be used' (Murray, 1997: 4). One prevailing metaphor, discussed by Murray, is that of the 'Information Superhighway'. This metaphor has become so common and so widespread that many people are fascinated by the notion of unlimited access to information and communications. However, this metaphor also invokes ethical issues in the form of questions such as: "Who will build the highway? Who will pay for its construction? Who will have access to it? Will it be a toll road or a freeway? Will travel be restricted, controlled? Who will police it?' (Murray, 1997: 2).

\section{Beyond the language of critique}

What can be concluded from the above critiques is that, as people and as educators, we must ensure that we do not see a particular metaphor as describing the way all human beings think, but rather as determining how we view and use the technology. We must also be able to see power struggle as a struggle over meaning and representation, that is, who defines and assigns meaning. We must apply our knowledge and understanding about multiple intelligences and learning styles as much to decisions we make about computer use in our classrooms as we do to decisions about group work or visual aids. Besides, we need to reflect on other metaphors used to describe the new technology, to deconstruct the metaphors for ourselves and ensure that our pedagogical decisions are not based on flawed or insidious metaphors. This means that the questions of 'how, where, why, and by whom' this computer technology is used are all legitimate to ask because, as noted by Riel (1990), 'new tools alone do not create educational change. The power is not in the tool but in the community that can be brought together and the collective vision that they share for redefining classroom learning.'

From a critical perspective on the data, it can be seen that the prevailing tendency among ESL/EFL pre-service teachers has often been to deal with computer technology as a neutral tool and to ignore its role in the socio-economic, and political dynamics of culture. The cultural strategy of appropriation is very useful in redefining and redirecting the use of computer technology for counter-hegemonic purposes (Tidwell, 1993). Data analysis showed that the predominant tendency among participants in the TESOL programme was to reinforce further the hegemonic aspects of education via CALL. Hence, the suggestions for improving the programme and the need for integrating a critical perspective (e.g. Bowers, 1988; Jones, 1995; Morton, 1996; Murray, 1997; Pennington, 1996; and Wise, 1995 ) into the use of CALL in TESOL teacher education programmes.

Thus, ESL/EFL teachers need to be aware of the reality that computer technology brings with it. Otherwise, instead of developing $\mathrm{CCCC}$ in the learner via email and Internet, this mode of computer use may foster students' stereotypes and biases, especially when the focus is on cultural products rather than processes, and enhance existing disparities in terms of class, ethnic and gender privileges. The data reported in this article reinforce the view that most of the students feel that computer technology is neutral without a critical consideration of its role in the socio-cultural dynamics of society. The following suggested recommendations and classroom implications aim at improving the quality of CALL in the TESOL teacher education programmes in their attempt to develop pre-service teachers' CCCC. 


\section{Recommendations and pedagogical implications}

To provide ESL/EFL learners with quality education on/via computers, computer systems 'should be viewed as structured learning environments with complex and comprehensive capabilities to access and manipulate information' (Morton, 1996: 417). In addition to providing accessibility and availability of updated hardware and software equipment, the role of a supportive computer-based environment is to provide technical training and scaffolding for both ESL/EFL learners and ESL/EFL teachers to develop their critical and effective technological competence. The TESOL programme does not yet provide such technical training for all students, as was recognized by all participants in the study. As one of them remarked: 'Like I said I haven't had experience with technology in this program. I think there is a lot to be explored yet.' In fact, CALL courses do not figure on the list of core courses of this particular MA TESOL programme or on the list of elective courses. This is why all participants (100 per cent) expressed their dissatisfaction with the way computer technology is being used in their programme.

To develop effective critical technological competence, TESOL teacher education programmes need to move beyond a view that embraces computer technology without questioning its non-neutrality and without understanding its role in the socio-cultural processes. They also need to move beyond a view of computers as add-ons which also encourage traditional instructional strategies and exclude computer-based learning and teaching from the curriculum (Morton, 1996). One of the participants said: 'They have to use good technology, because I cannot imagine a program like that without having some introductory courses to CALL, for example.' However, simply adding a computer or a course to a classroom or programme in a school has not ensured that the teachers use the technology effectively for the purpose of teaching and learning (Okolo, Bahr and Rieth, 1993).

Computer projects and classroom activities that democratize the educational process and help prospective teachers develop their CCCC are highly recommended. For example, computer use in on-line communication can result in community building, in which individuals collectively solve problems and provide support for each other in a democratic and egalitarian manner (see, for example, Bruce, Peyton and Batson, 1993; Harris, 1993; Rice-Lively, 1994; and Schrum, 1995). This type of communication, according to Warschauer (1996), can be asynchronous through tools such as email, which allow each participant to compose messages at their own time and pace, or synchronous (real time), using programmes such as MOOs (Multi-user Object-Oriented) on-line communication. It also allows not only one-to-one communication, but also one-to-many, allowing a teacher or student to share a message with a small group, the whole class, a partner class or an international discussion list of hundreds or thousands of people.

Computer-mediated communication (CMC) allows users to share not only brief messages, but lengthy documents as well. Using the Web, students can search through millions of files around the world within minutes to locate and access authentic materials and cultural information. Virtual Connections by Warschauer (1995) offers ESL/EFL teachers and learners a rich resource book in this regard. The 'New Ways in TESOL' (Boswood, 1997) series provides an excellent source of classroom activities on how to use the computer in the classroom for ESL/EFL learners/teachers. Other activity and strategy resources for 
integrating CALL in the development of CCCC can be found in Heinich, Molenda, Russell and Smaldino (1999), Lockard et al. (1997), Morrison, Lowther and DeMeulle (1999), and Poole (1997).

However, ESL/EFL educators need to be cautious as to the selection of CALL software. Warschauer (1996) points out several major problems that have surfaced in the use of CALL software in language teaching programmes:

- First, there is the question of quality of available programs. While some teachers themselves can develop their own multimedia programs using authoring software such as Hypercard (for Macintosh) or Toolbook (for PC), most classroom teachers lack the training or the time to make even simple programs. This has left the field to commercial software developers, who often do not base their programs on sound pedagogical principles, let alone consider critical emancipatory objectives related to CALL and its socio-cultural dynamics, as discussed in this article.

- Secondly, the cost for developing quality programs can price them out of the market of most English teaching programmes.

- Thirdly, some of today's computer programs are not yet intelligent enough to be truly interactive. For example, one particular program used in this area (Dustin) should ideally be able to understand a user's spoken input and evaluate it, not just for correctness but for appropriateness as well.

Finally it should be emphasized that EFL/ESL teachers should be educated to become not only critical intellectuals but transformative intellectuals as well (Giroux, 1981, 1992; McLaren, 1998). In other words, they should base their classroom practice, in developing CCCC via CALL in students, on a critical view of culture that starts where the learners are and focuses on unequal relations of power and means to address inequalities. Besides, they should not only know 'what and how to teach' but also 'why' they teach 'what' they teach 'the way' they teach it (Edge, 1996; Crookes, 1997). In this way they will actively seek to empower themselves and their students to reconstruct society so that it better serves the needs and interests of all groups of people. This is an especially cogent framework in this historical period known as the information age.

\section{References}

Aronowitz, S., and Giroux, H. A. (1993), Education Still under Siege (2nd edn), South Hadley, MA.: Bergin and Garvey.

Boswood, T. (ed.) (1997), New Ways of Using Computers in Language Teaching, New ways in TESOL series II', Alexandria, VA: TESOL.

Bowers, C. A. (1988), The Cultural Dimensions of Educational Computing: Understanding the Non-neutrality of Technology, New York: Teachers College Press.

Bruce, B., Peyton, J. K. and Batson, T. (1993), Network-based Classrooms: Promises and Realities, New York: Cambridge University Press.

Celce-Maurcia, M. (1991), Teaching English as a Second or Foreign Language (2nd edn), Boston, MA: Heinle and Heinle. 
Crookes, G. (1997), 'What influences what and how second and foreign language teachers teach?', The Modern Language Journal, 18 (1), 67-79.

Edge, J. (1996), 'Cross-cultural paradoxes in a profession of values', TESOL Quarterly, 30 (1), 9-30.

Ely, M., Anzul, M., Friedman, T., Garner, D. and Steinmetz, A. M. (1991), Doing Qualitative Research: Circles within Circles, London: Falmer.

Foley, D. (1990), Learning Capitalist Culture: Deep in the Heart of Tejas, Philadelphia, PA: University of Pennsylvania Press.

Gebhard, J. G. (1996), Teaching English as a Foreign Language: A Self-development Guide, Ann Arbor, MI: University of Michigan Press.

Giroux, H. A. (1981), Ideology, Culture and the Process of Schooling, Barcombe, UK: Falmer Press.

Giroux, H. (1992), 'Critical literacy and student experience: Donald Graves' approach to literacy', in P. Shannon (ed.), Becoming Political: Readings and Writings in the Politics of Education, Portsmouth, NH: Heinemann.

Harris, J. B. (1993), 'An Internet-based graduate telecomputing course: practicing what we preach', in D. Carey, R. Carey, D. A. Willis, and J. Willis (eds), Technology and Teacher Education Annual, Charlottesville, VA: Association of Advancement of Computing in Education, 641-5.

Heinich, R., Molenda, M., Russell, J. D. and Smaldino, S. E. (1999), Instructional Media and Technologies for Learning (6th edn), Upper Saddle River, NJ: Prentice-Hall.

Jones, J. G. (1995), Cybersociety: Computer-mediated Communication and Community, Thousand Oaks, CA: Sage.

Lockard, J., Abrams, P. D. and Many, W. A. (1997), Microcomputers for Twenty-first Century Educators (4th edn), New York: Longman.

McGrath, D., Thurston, L. P., McLellan, H., Stone, D. and Tischhauser, M. (1992), 'Sex differences in computer attitudes and beliefs among rural middle school children after a teacher training intervention', Journal on Computing in Education, 24 (4), 468-85.

McLaren, P. (1998), Life in Schools: An Introduction of Critical Pedagogy in the Foundations of Education, New York: Longman.

Miles, M. B., and Huberman, A. M. (1994), Qualitative Data Analysis: An Expanded Sourcebook (2nd edn), Thousand Oaks, CA: Sage.

Morrison, G. R., Lowther, D. L. and DeMeulle, L. (1999), Integrating Computer Technology into the Classroom, Upper Saddle River, NJ: Prentice-Hall.

Morton, C. (1996), 'The Modern Land of Laputa: where computers are used in education', Phi Delta Kappa (February, 1996), 416-19.

Murray, D. E. (1997), Language and Society in Cyberspace, available at http:/lwww.tesol.edulassoclarticles/news9808-03.html. 
Okolo, C., Bahr, C. and Rieth, H. (1993), 'A retrospective view of computer-based instruction', Journal of Special Technology, 7 (2), 11-14.

Pennington, M. C. (ed.) (1996), The Power of CALL, Houston, TX: Athelstan.

Phillipson, R. (1992), Linguistic Imperialism, Oxford: Oxford University Press.

Poole, B. (1997), Education for an Information Age: Teaching in the Computerized Classroom (2nd edn), Boston, MA: McGraw-Hill.

Ramírez, A. G. and Hall, J. K. (1990), 'Language and culture in secondary Spanish textbooks', Modern Language Journal, 74 (1), 48-65.

Rice-Lively, M. L. (1994), 'Wired warp and woof: an ethnographic study of a networking classroom', Internet Research, 4 (4), 20-35.

Riel, M. (1990), Building a New Foundation for Global Communities, The Writing Notebook (January/February), 35-7.

Samovar, L. A., and Porter, R. E. (1997), Intercultural Communication: A Reader, Belmont, CA: Wadsworth.

Schrum, L. (1995), 'Educators and the Internet: a case study of professional development', Computers and Education, 24 (3), 221-8.

Sehlaoui, A. S. (1999), 'Developing cross-cultural communicative competence in ESL/EFL pre-service teachers: a critical perspective', doctoral dissertation, Indiana University of Pennsylvania, Dissertation Abstracts International, DAI-A 60106, 2042, Publication No. 99348338.

Shannon, P. (1992), Becoming Political: Readings and Writings in the Politics of Literacy Education, Portsmouth, NH: Heinemann.

Sleeter, C. E. and Grant, C. (1999), Making Choices for Multicultural Education: Five Approaches to Race, Class, and Gender, Englewood Cliffs, NJ: Merrill Prentice-Hall.

Tidwell, M. (1993), 'Education for a change: appropriation and control in the Mayan refugees' school', unpublished doctoral dissertation, University of Pittsburgh, Pennsylvania.

Ur, P. (1996), A Course in Language Teaching: Practice and Theory, Cambridge: Cambridge University Press.

Warschauer, M. (1995), Virtual Connections: On-line Activities for Networking Language Learners, Second Language Teaching Curriculum Center: University of Hawai'i at Manoa.

Warschauer, M. (1996), 'Computer-assisted language learning: an introduction', in S. Fotos (ed.), Multimedia Language Teaching, Tokyo: Logos International, 3-20.

Wise, A. (1995), 'Raising expectations for technology in teacher education', NCATE Quality Teaching, 5(1), 2-3. 